\title{
The bird of time: cognition and the avian biological clock
}

\section{Vincent M. Cassone* and David F. Westneat}

Department of Biology, University of Kentucky, Lexington, KY, USA

\section{Edited by:}

Oliver Rawashdeh

Goethe-University Frankfurt,

Germany

Reviewed by:

Erik Maronde, University of

Frankfurt, Germany

Stuart E. Dryer, University of

Houston, USA

\section{${ }^{*}$ Correspondence:}

Vincent M. Cassone, Department of Biology, University of Kentucky, 101 Thomas Hunt Morgan Building, 675 Rose Street, Lexington 40506, KY, USA.

e-mail: vincent.cassone@uky.edu
Avian behavior and physiology are embedded in time at many levels of biological organization. Biological clock function in birds is critical for sleep/wake cycles, but may also regulate the acquisition of place memory, learning of song from tutors, social integration, and time-compensated navigation. This relationship has two major implications. First, mechanisms of the circadian clock should be linked in some way to the mechanisms of all these behaviors. How is not yet clear, and evidence that the central clock has effects is piecemeal. Second, selection acting on characters that are linked to the circadian clock should influence aspects of the clock mechanism itself. Little evidence exists for this in birds, but there have been few attempts to assess this idea. At its core, the avian circadian clock is a multi-oscillator system comprising the pineal gland, the retinae, and the avian homologs of the suprachiasmatic nuclei, whose mutual interactions ensure coordinated physiological functions, which are in turn synchronized to ambient light cycles (LD) via encephalic, pineal, and retinal photoreceptors. At the molecular level, avian biological clocks comprise a genetic network of "positive elements" clock and bmal1 whose interactions with the "negative elements" period 2 (per2), period 3 (per3), and the cryptochromes form an oscillatory feedback loop that circumnavigates the $24 \mathrm{~h}$ of the day. We assess the possibilities for dual integration of the clock with time-dependent cognitive processes. Closer examination of the molecular, physiological, and behavioral elements of the circadian system would place birds at a very interesting fulcrum in the neurobiology of time in learning, memory, and navigation.

Keywords: circadian, melatonin, pineal gland, bird song, caching, navigation, homing
"The Bird of Time has but a little way

To fly-and Lo! the Bird is on the Wing."

Omar Khayam, The Rubaiyat

Although all free-living organisms express biological rhythms in many, if not all, aspects of their biochemistry, cell biology, physiology, and behavior, biological clock function is particularly obvious in birds (Cassone et al., 2009), so much so that temporal metaphors of birdlife pervade our poetic and collective consciousness. The cock crows at sunrise. The nightingale sings in the evening. The early bird happens to get the worm. We recognize autumn by the sounds and splendor of geese flying south in their regiments of "vees," and spring springs eternal with the coming of spring migrants and the advent of birdsong in our gardens. As such, it is not surprising that some of the earliest scientific analyses of biological clock function and organization arise from work in birds. In some poetic sense, as is stated in The Rubaiyat, birds are time, and, scientifically, much of the study of birds is an exercise in the study of biological time-keeping.

As early as 1926, pursuing earlier suggestions that light may be a factor in annual cycles of birds (Schäfer, 1907), William Rowan showed that the timing of avian migration resulted from a clocklike perception of changing photoperiod (Rowan, 1926). Since then, much work has been conducted that places the avian biological clock system among the best characterized mechanisms of biological time-keeping. That said, there are a growing number of findings from studies of the avian circadian clock that suggest our understanding of its inner workings and its role in a variety of behaviors is still incomplete. We first review what is known about the avian clock. We then explore the conceptual idea that because many aspects of behavior depend on timing, the mechanisms for regulating that behavior seem likely to connect with the clock mechanism. We review the evidence that such behaviors are influenced by the central clock rather than an independent timing mechanism.

\section{THE AVIAN CIRCADIAN CLOCK SYSTEM}

The avian circadian system is a complex of mutually coupled pacemakers residing in the pineal gland, retinae, and the avian homologs of the suprachiasmatic nucleus (SCN), synchronized to environmental light cycles (LD) by photoreceptors in the eye, pineal gland, and multiple sites within the brain (Figure 1; Cassone and Menaker, 1984). At the molecular level, genomic and transcriptional analyses have identified a highly conserved network of "clock genes" that are orthologous to clock genes identified in insects and mammals (Bailey et al., 2003; Karaganis et al., 2008, 2009). Although the biochemical details are not wellknown in birds, birds, like other species studied, express "positive elements" clock and bmall, which are transcribed rhythmically, translated in the cytoplasm, where they dimerize and enter the nucleus to activate the transcription of "negative elements" period 


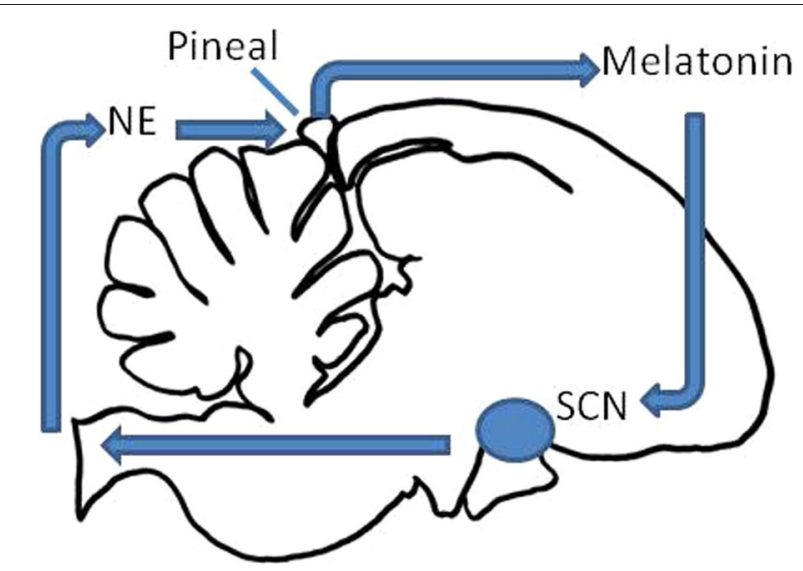

FIGURE 1 | Schematic of the avian circadian clock. The pineal gland secretes melatonin during the night, and inhibits the output of the $\mathrm{mSCN}$ and $v S C N$ (collectively the SCN here). The SCN in turn inhibits the output of the pineal gland through a multisynaptic pathway via the sympathetic nervous system and norepinephrine (NE).

2 (per2), period 3 (per3), cryptochrome 1 (cry1), and cryptochrome 2 (cry2), as well as other "clock-controlled genes" that rhythmically affect downstream processes. This network has been reviewed extensively elsewhere (Bell-Pedersen et al., 2005).

At the systems level, the pineal gland, the ocular retinae and the avian homologs to the suprachiasmatic nuclei form the nexus of biological clock function. The pineal gland is necessary for rhythmicity in passerine birds (Gaston and Menaker, 1968; Binkley et al., 1971), and rhythmic administration of the pineal hormone melatonin entrains circadian rhythms of several avian species (Chabot and Menaker, 1992; Lu and Cassone, 1993; Heigl and Gwinner, 1995). In galliforms (e.g., chicken and quail) and columbiforms (pigeons), the retinae are also important for circadian organization (Ebihara et al., 1984; Underwood and Siopes, 1984) since the eyes are major sources of melatonin in these species as well (Menaker, 1997). Thus, the common denominator for the role(s) played by the pineal gland and the retinae is likely the circadian secretion of melatonin.

In birds, two sets of structures have been associated with SCN function: the medial suprachiasmatic nuclei $(\mathrm{mSCN})$ and the visual suprachiasmatic nuclei (vSCN) (Cantwell and Cassone, 2006a,b) but their precise roles show some variation. These structures are connected via neuronal projections and are contiguous in terms of their cellular populations, especially in the distribution of astrocytes. The vSCN, but not the $\mathrm{mSCN}$, contains melatonin receptor binding (Cassone et al., 1995), and exogenous melatonin inhibits metabolic activity in the vSCN, but not in the mSCN (Cassone and Brooks, 1987; Lu and Cassone, 1993; Cantwell and Cassone, 2003). In Japanese quail, Coturnix coturnix, only the mSCN expresses clock gene rhythmicity (Yasuo et al., 2002), while in the house sparrow, Passer domesticus, both structures rhythmically express per2 (Abraham et al., 2002).

Each of these components is integrated dynamically such that overt circadian organization is synchronized to environmental LD and such that internal processes are adaptively orchestrated (Cassone and Menaker, 1984). Pineal (and retinal) melatonin, synchronized to LD cycles via endogenous photopigments (Figure 1; Kojima and Fukada, 1999), is secreted during the night and inhibits rhythmic metabolism and electrical activity of the vSCN. In turn, as the day approaches, oscillators within the pineal gland and retinae wane in their output, disinhibiting SCN activity. Oscillators within the $\mathrm{mSCN}$ and $\mathrm{vSCN}$ are active during the day, synchronized by LD via RHT input to the vSCN and possibly extraretinal input to the $\mathrm{mSCN}$. One of the outputs of the vSCN at least is the rhythmic regulation of sympathetic activity, releasing norepinephrine (NE) within many peripheral targets. Among these is the pineal gland, where NE inhibits melatonin biosynthesis and release. Pineal melatonin in turn inhibits metabolic activity in the vSCN in vivo (Lu and Cassone, 1993). In vitro, rhythmic melatonin administration synchronizes rhythms of both metabolic activity and the expression of both per2 and per3 (Paulose et al., 2009).

\section{AVIAN COGNITION AND TIMING}

Birds' have several extraordinary cognitive abilities, some of which rival those of the most advanced mammalian taxa, particularly among corvid (e.g., jays, crows, and ravens) and psittacine (parrots) species. We focus on three abilities that serve as examples of extraordinary capabilities of birds in which we have a fair understanding of the neural mechanisms and the ecological context. Each of these examples involves seasonal or daily rhythms, suggesting that the circadian clock could be involved.

In general, the neural substrates for avian cognition can be localized in the telencephalic pallia and are, therefore, in a general sense homologous to those in mammals, where the telencephalic neocortex appears to be the purview of higher order processing (Güntürkün, 2011). However, the location of specific structures within the telencephalon appears to be homoplastic, or convergent, in that the pallial regions of the telencephalon are differentially organized and reside in different aspects of the telencephalon. The hippocampal complex (HC), responsible for shortterm memory and place, is located in the dorsomedial aspects of the avian telencephalon, while the homologous mammalian $\mathrm{HC}$ is embedded within a laminar neocortex. Associative structures within the telencephala of mammals and birds appear to be completely homoplastic. While in mammals the prefrontal cortex is considered critical for cognitive functions associated with self-directed and task-specific planning, this behavioral capacity is controlled by the avian caudolateral nidopallium (NCL). Differences in the cytoarchitecture of these structures make it unlikely that they share either developmental or immediate phylogenetic ancestors. Yet, they each receive similar inputs from overlapping sensory modalities and are both regulated by extensive dopaminergic afferents arising from the ventral tegmentum during working memory tasks (Bast et al., 2002). Thus, birds and mammals have independently evolved higher cognitive skills by employing differentially organized forebrains.

\section{BIRD SONG AND BIRD SONG LEARNING}

There is growing evidence that the biological clock influences the timing of song production and learning. The song control system of oscine passeriform birds is a specialized network of brain nuclei involved in singing and song learning (Nottebohm 
et al., 1976; Konishi, 1989; Ball and Balthazart, 2010). This system receives auditory input from ascending auditory pathways which culminate in the forebrain. Song processing occurs in secondary auditory areas in the caudal mesopallium (cM) and caudomedial nidopallium (NCM), which interact with the anterior forebrain pathway (Figure 2A) for song plasticity and learning. This pathway includes the HVC in the dorsal forebrain, which projects to Area $\mathrm{X}$, whose projections form a loop between the dorsolateral thalamus (DLM) and the lateral magnocellular nucleus of the anterior nidopallium (LMAN). Then, both HVC and LMAN project to the robust nucleus of the archipallium (RA), which forms the song motor output pathway (Figure 2B).

This system enables birds to process a complex species-specific identification of both self and con-specifics as well as other dynamics in birds' acoustic environments (competitors, prey, predators, etc.). These acoustic environments as well as their reproductive and survival relevance are not constant. Territories change hands and the available range of mates fluctuates. In order to effectively interpret the acoustic features in song, the auditory system must structure its representation in such a way that
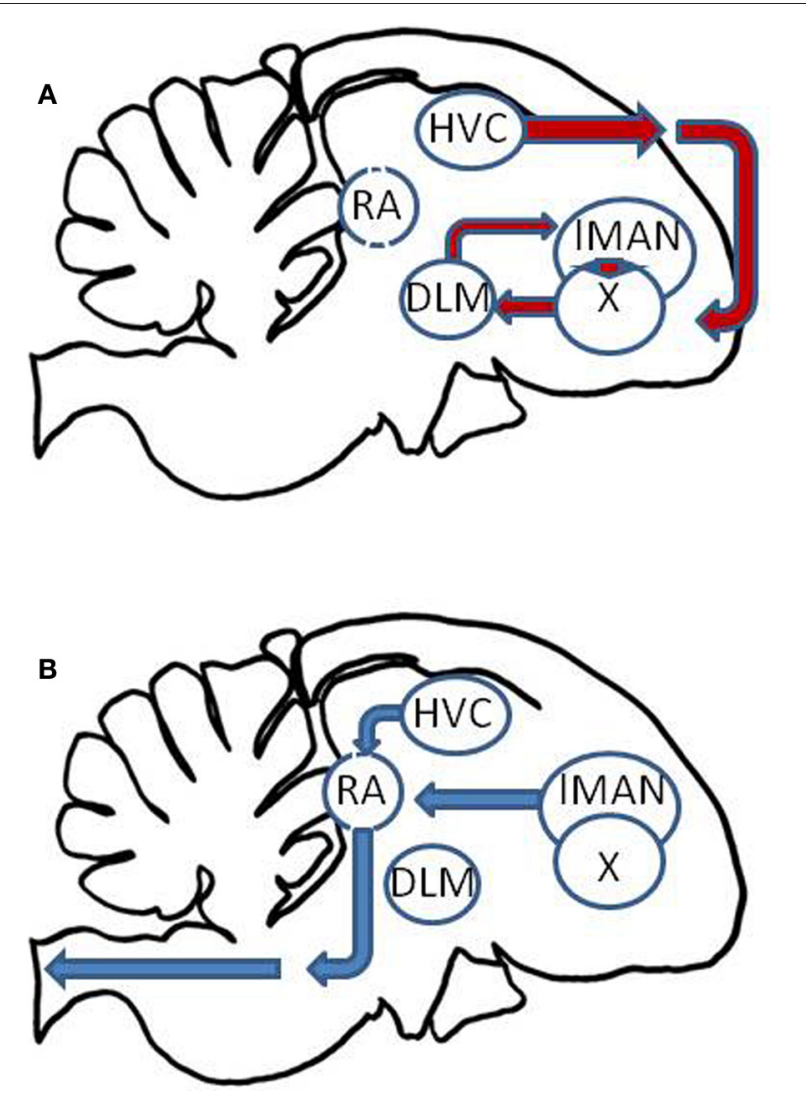

FIGURE 2 | Schematic of the passerine song control nuclei. (A) The anterior forebrain pathway involves a loop among the HVC, Area X (X), the dorsolateral thalamus (DLM), and the lateral magnocellular nucleus of the anterior nidopallium (IMAN). (B) These output through the song motor output pathway in which HVC and IMAN project to the robust nucleus of the archipallium (RA), which in turn projects to vocal motor pathways controlling the syrinx. allows for dynamic behavioral goals of the organism. At the same time, the structure and behavior of song itself must be tuned to reproductively appropriate situations.

Most oscine passeriform birds must learn their characteristic songs from a tutor bird. Some species, such as zebra finches, Taeniopygia guttata, and house sparrows, Passer domesticus, are "close-ended learners," in which song is learned from a tutor during a critical period early in development. Others, such as canaries, Serinus serinus, and European starlings, Sturnus vulgaris, are "open-ended learners," in which new motifs are added to birds' song over their lifetimes. In both cases, there are two phases of song learning. The first is the memorization of sensory phase, in which birds listen to a tutor song; this process is largely mediated by cM and NCM. The second phase is the sensorimotor phase in which juvenile birds produce "plastic song" that, after weeks of listening and practice, gradually "crystallizes" into adult song (Nottebohm et al., 1976; Konishi, 1989). This process is mediated by the anterior forebrain pathway.

Song learning is linked to timing in two ways. First, it exhibits daily patterns. An increasing body of evidence points to a central role for sleep in the sensorimotor phase of song learning (Margoliash, 2002). Electrophysiological recordings from RA and HVC during sleep with simultaneous electroencephalographic (EEG) recording to ascertain sleep state have shown that RA and HVC neurons fire during sleep, suggesting that cells within these structures "replay" songs learned during wakefulness (Nick and Konishi, 2001, 2005; Crandall et al., 2007; Shank and Margoliash, 2009). Intriguingly, Derégnaucourt et al. (2005) have found that night-time sleep decreases the power and increases entropy in vocalizations of young zebra finches. As a result, morning song is less precise than is afternoon song, as birds' vocalization becomes more repetitive over the course of the day. This daily dip in vocal precision diminishes in amplitude as birds' song crystallizes to adulthood, although it remains throughout birds' lives. These authors and others have suggested that playback during sleep prunes aberrant song patterns of plastic song the previous day and that sleep affects the quality of song the following day. In a surprisingly offhand remark, these authors state that injection of the pineal hormone melatonin into zebra finches during the day induced both a somnolent state for $2-3 \mathrm{~h}$ and the night-induced increase in vocal entropy.

Secondly, the song control nuclei HVC, RA, Area X, and lMAN of house sparrows, zebra finches, and starlings, Sturnus vulgaris, express high affinity melatonin receptors (Gahr and Kosar, 1996; Whitfield-Rucker and Cassone, 1996; Bentley et al., 1999; Jansen et al., 2005), raising the likelihood that the circadian clock system directly affects birdsong behavior and learning through the circadian secretion of melatonin by the pineal gland. To test this, Wang et al. (2012) pinealectomized adult male zebra finches and measured locomotor activity and vocalizations continuously. Pinealectomy abolished the circadian patterns of locomotor activity, song, and call. Song behavior, however, became arrhythmic several days earlier than did either locomotor activity or calls. When birds were administered melatonin rhythmically, rhythms in all three behaviors were reestablished, but, again, at different rates. Locomotor behavior was entrained to the melatonin regime more rapidly than song behavior which was entrained 


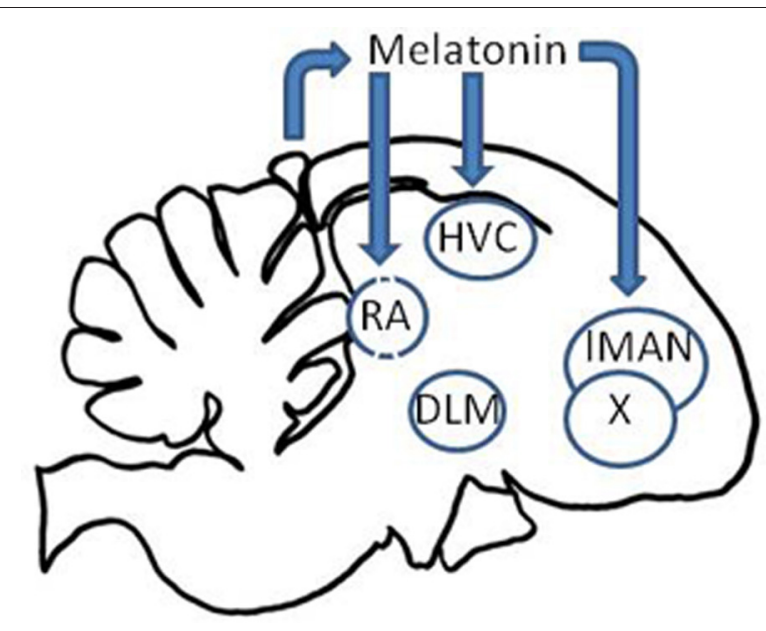

FIGURE 3 | The circadian clock influences the song control system through the secretion of melatonin via melatonin receptors in the HVC, IMAN, Area X, and RA.

more rapidly than was call behavior. The data indicate that the circadian clock in the pineal gland entrains separable circadian oscillators controlling locomotor, song, and call behavior and that these three behaviors are differentially sensitive to melatonin (Figure 3).

Song-learning is also linked to seasonal timing. Birds living in temperate zone latitudes generally restrict breeding to the spring and summer, maximizing the likelihood that young will be hatched during times at which food is plentiful (Ball and Balthazart, 2010; Kumar et al., 2010). As such, many primary and secondary sexual characteristics in birds undergo dramatic changes in both form and function. In the short days of winter, gonadal activity and gonad size are decreased. Similarly, both the probability of a male bird to sing in response to a given stimulus as well as the size and complexity of the song control nuclei within its brain vary depending upon the time of year. Birds in the short days of winter possess small HVC, RA, and depending on the species other structures in the system. When birds are photostimulated as photoperiod increases, the song control nuclei grow in parallel with the growth of the testes, and, as they become photorefractory, these structures regress in both size and complexity (Smith et al., 1997; Whitfield-Rucker and Cassone, 2000).

As stated above, one neuroendocrine correlate for photoperiod and season that is independent of gonadal function is the circadian secretion on pineal melatonin (Cassone, 1990a,b; WhitfieldRucker and Cassone, 1996). As the photoperiod lengthens from short days of winter to the long days of summer, the secretory pattern of melatonin shortens congruently. Thus, in a long summer day of $16 \mathrm{~h}$ of light and $8 \mathrm{~h}$ of darkness, the duration of melatonin in the blood of many temperate zone mammals and birds is short, approximately $8 \mathrm{~h}$ in length. Conversely, in a short winter day of $8 \mathrm{~h}$ of light and $16 \mathrm{~h}$ of darkness, the duration of melatonin is quite long. In seasonally breeding mammals, the duration of melatonin regulates the recrudescence and regression of the reproductive axis in appropriate, species-specific fashion. Thus, in short-day breeding ungulates such as sheep, long duration melatonin cycles induce reproductive activity, while in long-day breeding rodents, an identical long duration of melatonin results in gonadal regression.

In songbirds, the link between pineal melatonin and primary reproductive function is not as clear. Pinealectomy and manipulation of melatonin levels and durations have little effect on gonad size or steroid secretion (Gwinner and Brandstätter, 2001; Kumar et al., 2010). However, the presence of IMEL binding in song control structures raises the possibility that seasonal changes in melatonin duration, which are expressed by the avian pineal (Binkley, 1976; Brandstätter et al., 2000), may regulate bird song structures. To test this possibility, Cassone et al. (2008) compared the volumes of song control nuclei in house sparrows maintained in constant light (LL) that received either a long duration or a short duration of melatonin. Birds that received the short, summer-like duration of melatonin exhibited large, summer-like HVC and RA volumes. Birds that received a long duration, winterlike duration of melatonin exhibited small winter-like HVC and RA. No effect of the hormone was observed in testes size. Thus, melatonin not only synchronizes circadian patterns of vocal activity but also influences the seasonal changes in the song control apparatus (Figure 3). We do not know if the pineal hormone affects the learning of new vocalizations on a seasonal basis, but this would be a very fruitful area of research.

\section{SPATIAL ORIENTATION AND CACHING}

The simplest form of cognition in spatial orientation in birds is the ability to cache resources such as food or nest sites and then to remember their location at some time later. Several groups of birds are particularly adept at caching food, including parids such as chickadees and tits, corvids, and several species of owls. Food caching behavior has been compared to human "mental time travel" (Clayton et al., 2003) in that corvids, at least, not only express episodic memories of where a particular foodstuff has been stored, but also when it was stored and what type of food was stored. Secondly, these birds are able to plan retrieval of stored food for periods of days to months.

The HC appears to be critical for this behavioral capacity. First, food-storing birds such as jays (Corvidae) and chickadees (Paridae) have larger HCs, relative to the rest of the brain, than do non-storing birds such as house sparrows (Passeridae) and domestic pigeons, Columba livia (Order Columbiformes) (Krebs et al., 1989). Secondly, as with the song control system of oscine passeriform birds, the HC express adult de novo neurogenesis and food storing birds express greater rates of neurogenesis than do non-storing birds (Hoshooley and Sherry, 2007). Lesions in the HC impair the ability of chickadees to locate food caches but have little effect on cognitive performances in other modalities, suggesting the $\mathrm{HC}$ is specifically involved in spatial memory (Sherry and Vaccarino, 1989; Hampton and Shettleworth, 1996).

There is no direct evidence that either the molecular components of circadian clocks or any neural structure associated with biological clocks influence this form of spatial orientation. Very little or no reported research has been conducted on whether food caching behavior follows daily or circadian patterns. However, most food caching behavior follows distinct seasonal patterns that are clearly regulated by photoperiod (Sherry and Hoshooley, 
2010). In most cases, caching occurs primarily in fall, when food is predictable and abundant, and retrieved in the winter, when food supplies are reduced and become more unpredictable. Even so, small food-caching birds will retrieve their cache within a few days, but some species may store food for long periods of time. For example, Clark's nutcrackers, Nucifraga columbiana, which live in montane regions of North America, store pine nuts during the autumn when they are abundant, migrate to lower altitudes for the winter, and then retrieve their caches in the spring when they return to breed before vernal growth produces other sources of food (Tomback, 1978). These birds reproduce this very longterm spatial memory under laboratory conditions (Gould et al., 2012).

As with the song control system described above, there is some evidence that the $\mathrm{HC}$ varies in size depending on the time of year, being larger from late winter and spring than in the fall (Hoshooley and Sherry, 2007). However, the effect is much smaller than it is within the song control system and it is also inconsistent, depending on the year and latitude of the study (Sherry and Hoshooley, 2010). Even so, the HC of chickadees express seasonal patterns of neurogenesis, such that neurogenesis occurs predominantly in winter and spring irrespective of whether the HC changes size, suggesting that this process entails neuron replacement rather than growth. To date, no studies have been done assessing whether any brain or behavior associated with caching is influenced by melatonin, but we predict that this will be the case. As with song, we also predict the exact form by which the central clock influences caching may vary among species and possibly even populations having different ecologies.

\section{TIME-COMPENSATED, SUN COMPASS NAVIGATION}

One of the great mysteries of animal behavior surrounds the abilities of birds to migrate over great distances, to identify appropriate breeding, and/or feeding sites at the appropriate time of year and to return to their home consistently and accurately. At the face of it, these behaviors are impressive cognitive feats, and they are embedded in birds' sense of time at several different levels. First, migratory birds are genetically imbued with a temporal program that enables them to migrate with a general direction and distance in their first year as naïve migrants. In addition, the birds modify their trajectories and timing as they learn the migratory route, implying a cognitive adaptation (Gwinner, 1996). Secondly, homing pigeons and presumably all birds that use timecompensated navigation employ their internal circadian clock to integrate the progression of the sun's azimuth to achieve a bearing toward home. Birds can use this ability to learn the location of a desired object or place. Exactly how the circadian clock integrates with each of these mechanisms is not yet known, but several hints are suggestive.

While memory of caches described above can require flight over reasonably large distances for retrieval, as is the case with the nutcrackers, most caching behaviors require only orientation and memory of landmarks in relatively close proximity. In many other situations, birds are known to travel great distances during transcontinental migration or homing (Kalmus, 1964; Gwinner, 2003). In these cases, birds are believed to employ a wide array of cognitive forms of compasses and maps to enable them to locate their current position, orient toward the new location or home, and navigate the distance accurately, including odor, magnetic fields, and the sun compass (Wiltschko, 1991).

Sun compass or time-compensated navigation was first described in honeybees by Von Frisch (cf. 1967) in which bees learn to visit a particular food source at a particular time of day and convey that information to the hive via the famous waggle dance. Using this information, bees navigate to the food source by interpolating the position of the sun's azimuth with the bees' internal sense of time. The fact that an internal sense of time (Zeitgedachnis) was required for this navigation was demonstrated by shifting the light: dark cycles of the hive by $6 \mathrm{~h}$ (or $90^{\circ}$ of the $24 \mathrm{~h} 360^{\circ}$ day) and showing that bees consistently make a $90^{\circ}$ error in orientation. This capacity has also been demonstrated in several species of birds, including European starlings and domestic pigeons (Kramer, 1959; Kalmus, 1964). One question that has arisen from these studies was whether the internal sense of time was one and the same as the biological circadian clock. In an elegant series of studies, Hoffmann (1960) showed that starlings maintained in constant dim light exhibited gradual shifting in orientation with a period equivalent to the period of their free-running rhythms in locomotion. These data suggested that the orientation clock and the circadian clock shared clock properties, but the studies were conducted before any neurobiological or molecular components of the clock had been identified. That mystery still remains.

However, Bingman and colleagues have asked whether homing pigeons can learn and remember an orientation by employing their sun compass (Bingman and Gagliardo, 2006). Pigeons were taught to identify a door in an outdoor octagonal arena that contained seed for food at a particular time of day. Then, to determine whether the pigeons were using their sun compass, subject birds were returned to the laboratory where their light cycles were phase delayed $6 \mathrm{~h}\left(90^{\circ}\right)$. When birds were tested after the shift, those that employed their sun compass to orient to the food cup consistently made a $90^{\circ}$ error to the right (clockwise!). Bingman and colleagues then asked whether this task involved HC place memory by lesioning the HC before the training sessions (Bingman and Jones, 1994). Lesion of the left HC interfered with pigeons' ability to locate the food using the sun compass but had no effect on birds' ability to use other cues (Gagliardo et al., 2005). This process could be replicated using an artificial "sun" in the laboratory (Petruso et al., 2007) and in the field, when birds were released and followed by GPS tracking (Gagliardo et al., 2009). Thus, pigeons can learn to use their internal biological clock during a cognitive task, but whether it is directly connected to the central clock and how it interacts with structures associated with cognition are unanswered questions.

\section{IS MELATONIN THE LINK BETWEEN CLOCKS AND COGNITION?}

Birds are capable of very complex behavior and possess impressive cognitive skills (Hunt, 1996, 2002; Emery et al., 2007; Taylor et al., 2007; Grodzinski and Clayton, 2010). These behaviors and cognitive skills are modulated by biological clocks 
on a circadian and circannual bases. Yet, in most cases, a direct link of higher order behaviors requiring learning and memory to known structures and gene products associated with biological timing are not known. The one exception is the presence of melatonin receptors within the avian song control system, and the effects of pinealectomy and melatonin on song behavior. Still, these studies have yet to show an effect of melatonin on the learning of song. It is true that migratory behavior in nocturnal migrants appears to be influenced by the amplitude of melatonin (Fusani and Gwinner, 2006). In addition, the HC of pigeons also express melatonin receptors, but it is not known whether migratory birds similarly express them (Cassone et al., 1995). Normally diurnal birds that migrate during the night exhibit lower amplitude rhythms of melatonin during periods of migratory restlessness, Zugunruhe, than at other times of year. This observation has led Gwinner and colleagues (Gwinner and Brandstätter, 2001; Gwinner, 2003) to suggest that the reduction in the amplitude of melatonin cycles reflect a reduction in the amplitude of the clock itself, enabling birds to eschew sleep during this period of increased activity and to shift time zones rapidly. It is not clear whether this is a change in sensitivity to the clock's output, or a change in the cycling of the clock itself. Moreover, there is no indication yet that the pineal or its hormone melatonin influences the what-when-where cognition associated with both food caching and migration or navigation.

This is an area that could be very fruitful for future research. Because birds express such complex, yet experimentally tractable, cognitive behaviors and because the details of biological clock function in birds are becoming clearer every day, research in the roles the clock plays in cognition and in ways by which birds cognitively employ their clocks will tell us much about the regulation of complex behavior in all animals, even humans.

\section{REFERENCES}

Abraham, U., Albrecht, U., Gwinner, E., and Brandstätter, R. (2002). Spatial and temporal variation of passer Per2 gene expression in two distinct cell groups of the suprachiasmatic hypothalamus in the house sparrow (Passer domesticus). Eur. J. Neurosci. 16, 429-436.

Bailey, M. J., Beremand, P. D., Hammer, R., Bell-Pedersen, D., Thomas, T. L., and Cassone, V. M. (2003). Transcriptional profiling of the chick pineal gland, a photoreceptive circadian oscillator and pacemaker. Mol. Endocrinol. 17, 2084-2095.

Ball, G. F., and Balthazart, J. (2010). Seasonal and hormonal modulation of neurotransmitter systems in the song control circuit. J. Chem. Neuroanat. 39, 82-95.

Bast, T., Diekamp, B., Thiel, C., Schwarting, R. K., and Güntürkün, O. (2002). Functional aspects of dopamine metabolism in the putative prefrontal cortex analogue and striatum of pigeons (Columba livia). J. Comp. Neurol. 446, 58-67.

Bell-Pedersen, D., Cassone, V. M., Earnest, D. J., Golden, S. S., Hardin, P. E., Thomas, T. L., and Zoran, M. J. (2005). Circadian rhythms from multiple oscillators: lessons from diverse organisms. Nat. Rev. Genet. 6, 544-556.

Bentley, G. E., Van't Hof, T. J. and Ball, G. F. (1999). Seasonal neuroplasticity in the songbird telencephalon: a role for melatonin. Proc. Natl. Acad. Sci. U.S.A. 96, 4674-4679.

Bingman, V. P., and Jones, T. J. (1994). Sun compass-based spatial learning impaired in homing pigeons with hippocampal lesions. J. Neurosci. 14(11 Pt 1), 6687-6694.

Bingman, V. P., and Gagliardo, A. (2006). Of birds and men: convergent evolution in hippocampal lateralization and spatial cognition. Cortex 42, 99-100.

\section{SUMMARY}

Our review of the linkages between the avian circadian clock and several cognitive tasks that birds are famous for doing strongly suggest that there are direct links between the mechanism of the clock and aspects of the cognitive task. Appropriate timing of behavior could be under strong selection, which might favor one of two outcomes. First, the central clock could have different, and potentially modulated, effects on different behavioral mechanisms. Some evidence exists for this but more research into this possibility and how it is accomplished would be fruitful. Another potential response to selection on timing is that elements of some cognitive tasks might feedback to influence the clock. Singing by conspecifics or the sight of cachable food (or even the act of caching) might alter the periodicity of the central clock. The evidence for this in birds is very weak, and so our ideas remain hypothetical and based only on the principle that selection will shape mechanisms for time-keeping to produce behaviors when they will have the greatest benefit. We note that such feedback to the general clock mechanism may be constrained-given that the clock regulates multiple tasks that may be on different schedules, it is possible that it will either be relatively inflexible to stimuli arising from one of the many tasks it regulates, or that in some cases there will be multi-channel clocks-sets of linked mechanisms that produce generally similar patterns of timing but also have some level of independence due to tight connections with behavioral activities that are on somewhat different schedules. Each of these possibilities generates questions that run the gamut from molecular mechanisms to evolution in the face of constraints. Birds provide an extraordinary opportunity to explore these ideas because the ecological context of their activities can be studied alongside the neural and hormonal mechanisms that influence them.

Binkley, S., Kluth, E., and Menaker, M. (1971). Pineal function in sparrows: circadian rhythms and body temperature. Science 174, 311-314.

Binkley, S. (1976). Pineal gland biorhythms: N-acetyltransferase in chickens and rats. Fed. Proc. 35 2347-2352.

Brandstätter, R., Kumar, V., Abraham U., and Gwinner, E. (2000) Photoperiodic information acquired and stored in vivo is retained in vitro by a circadian oscillator, the avian pineal gland Proc. Natl. Acad. Sci. U.S.A. 97, 12324-12328.

Cantwell, E. L., and Cassone, V. M. (2002). Daily and circadian fluctuation in 2-deoxy[(14)C]-glucose uptake in circadian and visual system structures of the chick brain effects of exogenous melatonin. Brain Res. Bull. 57, 603-611.

Cantwell, E. L., and Cassone, V. M. (2006a). The chicken suprachiasmatic nuclei: I. Efferent and afferent connections. J. Comp. Neurol. 496, 97-120.

Cantwell, E. L., and Cassone, V. M. (2006b). The chicken suprachiasmatic nucleus: II. Autoradiographic and immunohistochemical analyses. J. Comp. Neurol. 499, 442-457.

Cassone, V. M. (1990a). Effects of melatonin on vertebrate circadian systems. Trends Neurosci. 13, 457-464.

Cassone, V. M. (1990b). Melatonin: time in a bottle. Oxf. Rev. Reprod. Biol. 12, 319-367.

Cassone, V. M., Bartell, P. A., Earnest, B. J., and Kumar, V. (2008). Duration of melatonin regulates seasonal changes in song control nuclei of the house sparrow, Passer domesticus: independence from gonads and circadian entrainment. J. Biol. Rhythms 23, 49-58.

Cassone, V. M., and Brooks, D. S. (1991). The sites of melatonin action in the house sparrow brain. J. Exp. Zool. 260, 302-309. 
Cassone, V. M., Brooks, D. S., and Kelm, T. A. (1995). Comparative distribution of 2[125I]iodomelatonin binding in the brains of diurnal birds: outgroup analysis with turtles. Brain Behav. Evol. 45, 241-256.

Cassone, V. M., and Menaker, M. (1984). Is the avian circadian system a neuroendocrine loop? J. Exp. Zool. 232, 539-549.

Cassone, V. M., Paulose, J. K., Whitfield-Rucker, M. G., and Peters, J. L. (2009). Time's arrow flies like a bird: two paradoxes for avian circadian biology. Gen. Comp. Endocrinol. 163, 109-116.

Chabot, C. C., and Menaker, M. (1992). Effects of physiological cycles of infused melatonin on circadian rhythmicity in pigeons. J. Comp. Physiol. A 170, 615-622.

Clayton, N. S., Bussey, T. J., and Dickinson, A. (2003). Can animals recall the past and plan for the future? Nat. Rev. Neurosci. 4, 636-645.

Crandall, S. R., Adam, M., Kinnischtzke, A. K., and Nick, T. A. (2007). HVC neural sleep activity increases with development and parallels nightly changes in song behavior. J. Neurophysiol. 98, 232-240.

Derégnaucourt, S., Mitra, P. P., Fehér, O., Pytte, C., and Tchernichovski, O. (2005). How sleep affects the developmental learning of bird song. Nature 433, 710-716.

Ebihara, S., Uchiyama, K., and Oshima, I. (1984). Circadian organization in the pigeon, Columba livia. J. Comp. Physiol. A. 154, 59-69.

Emery, N. J., Seed, A. M., von Bayern, A. M., and Clayton, N. S. (2007). Cognitive adaptations of social bonding in birds. Philos. Trans. R. Soc. Lond. B Biol. Sci. 362, 489-505.

Fusani, L., and Gwinner, E. (2006). Melatonin and nocturnal migration. Ann. N.Y. Acad. Sci. 1046, 264-270.

Gagliardo, A., Ioalè, P., Savini, M., Dell'Omo, G., and Bingman, V. P. (2009). Hippocampaldependent familiar area map supports corrective re-orientation following navigational error during pigeon homing: a GPStracking study. Eur. J. Neurosci. 29, 2389-2400.

Gagliardo, A., Vallortigara, G., Nardi, D., and Bingman, V. P. (2005). A lateralized avian hippocampus: preferential role of the left hippocampal formation in homing pigeon sun compass-based spatial learning. Eur. J. Neurosci. 22, 2549-2559.

Gahr, M., and Kosar, E. (1996). Identification, distribution, and developmental changes of a melatonin binding site in the song control system of the zebra finch. J. Comp. Neurol. 367, 308-318.

Gaston, S., and Menaker, M. (1968). Pineal function: the biological clock in the sparrow? Science 160, 1125-1127.

Gould, K. L., Ort, A. J., and Kamil, A. C. (2012). Do Clark's nutcrackers demonstrate what-where-when memory on a cache-recovery task? Anim. Cogn. 15, 27-34.

Grodzinski, U., and Clayton, N. S. (2010). Problems faced by foodcaching corvids and the evolution of cognitive solutions. Philos. Trans. R. Soc. Lond. B Biol. Sci. 365, 977-987.

Güntürkün, O. (2011). The convergent evolution of neural substrates for cognition. Psychol. Res. [Epub ahead of print] PubMed PMID: 21881941

Gwinner, E. (1996). Circadian and circannual programmes in avian migration. J. Exp. Biol. 199(Pt 1), 39-48.

Gwinner, E. (2003). Circannual rhythms in birds. Curr. Opin. Neurobiol. 13, 770-778.

Gwinner, E., and Brandstätter, R. (2001). Complex bird clocks. Philos. Trans. R. Soc. Lond. B Biol. Sci. 356, 1801-1810.

Hampton, R. R., and Shettleworth, S. J. (1996). Hippocampal lesions impair memory for location but not color in passerine birds. Behav. Neurosci. $110,831-835$.

Heigl, S., and Gwinner, E. (1995). Synchronization of circadian rhythms of house sparrows by oral melatonin: effects of changing period. J. Biol. Rhythms 10, 225-233.

Hoffmann, K. (1960). Experimental manipulation of the orientational clock in birds. Cold Spring Harb. Symp. Quant. Biol. 25, 379-387.

Hoshooley, A. F., and Sherry, D. F. (2007). Greater hippocampal neuronal recruitment in food-storing than in non-food-storing birds. Dev. Neurobiol. 67, 406-414.

Hunt, G. (1996). Manufacture and use of hook-tools by New Caledonian crows. Nature 379, 249-251.

Hunt, G. (2002). Tool use by the New Caledonian crow Corvus moneduloides to obtain Cerambycidae from dead wood. Emu 100, 109-114.

Jansen, R., Metzdorf, R., vander Roest, M., Fusani, L., ter Maat, A., and
Gahr, M. (2005). Melatonin affects the temporal organization of the song of the zebra finch. FASEB J. 19 , 848-850.

Kalmus, H. (1964). Comparative physiology: navigation by animals. Annu. Rev. Physiol. 26, 109-130.

Karaganis, S. P., Bartell, P. A., Shende, V. R., Moore, A. F., and Cassone, V. M. (2009). Modulation of metabolic and clock gene mRNA rhythms by pineal and retinal circadian oscillators. Gen. Comp. Endocrinol. 161, 179-192.

Karaganis, S. P., Kumar, V., Beremand, P. D., Bailey, M. J., Thomas, T L., and Cassone, V. M. (2008) Circadian genomics of the chick pineal gland in vitro. BMC Genomics 9, 206.

Kojima, D., and Fukada, Y. (1999). Non-visual photoreception by a variety of vertebrate opsins. Novartis Found. Symp. 224 265-279.

Konishi, M. (1989). Birdsong for neurobiologists. Neuron 3, 541-549.

Kramer, G. (1959). Recent experiments on bird orientation. Ibis 101, 399-416.

Krebs, J. R., Sherry, D. F., Healy, S. D., Perry, V. H., and Vaccarino, A. F. (1989). Hippocampal specialization of food storing birds. Proc. Natl. Acad. Sci. U.S.A. 86, 1388-1392.

Kumar, V., Wingfield, J. C., Dawson, A., Ramenofsky, M., Rani, S. and Bartell, P. (2010). Biological clocks and regulation of seasonal reproduction and migration in birds. Physiol. Biochem. Zool. 83 827-835.

Lu, J., and Cassone, V. M. (1993) Daily melatonin administration synchronizes circadian patterns of brain metabolism and behavior in pinealectomized house sparrows, Passer domesticus. J. Comp. Physiol. A 173, 775-782.

Margoliash, D. (2002). Evaluating theories of bird song learning: implications for future directions. J. Comp. Physiol. A Neuroethol. Sens. Neural Behav. Physiol. 188, 851-866.

Menaker, M. (1997). Commentary: what does melatonin do and how does it do it? J. Biol. Rhythms 12 532-534.

Nick, T. A., and Konishi, M. (2001). Dynamic control of auditory activity during sleep: correlation between song respone and EEG Proc. Natl. Acad. Sci. U.S.A. 98, 14012-14016.

Nick, T. A., and Konishi, M. (2005). Neural song preference during vocal learning in the zebra finch depends on age and state. J. Neurobiol. 62, 231-242.

Nottebohm, F., Stokes, T. M., and Leonard, C. M. (1976). Central control of song in the canary, Serinus canaries. J. Comp. Neurol. 165, 457-486.

Paulose, J. K., Peters, J. L., Karaganis, S. P., and Cassone, V. M. (2009). Pineal melatonin acts as a circadian zeitgeber and growth factor in chick astrocytes. J. Pineal Res. 46, 286-294.

Petruso, E. J., Fuchs, T., and Bingman, V. P. (2007). Time-space learning in homing pigeons (Columba livia): orientation to an artificial light source. Anim. Cogn. 10, 181-188.

Rowan, W. (1926). On photoperiodism, reproductive periodicity and the annual migration of birds and certain fishes. Proc Boston Soc. Nat. History 38, 147-189.

Schäfer, E. A. (1907). On the incidence of daylight as a determining factor in bird migration. Nature 77, 159-163.

Shank, S. S., and Margoliash, D. (2009). Sleep and sensorimotor integration during early vocal learning in a songbird. Nature 458 , 73-77.

Sherry, D. F., and Hoshooley, J. S (2010). Seasonal hippocampal plasticity in food-storing birds. Phil. Trans. Royal Soc. B 365, 933-943.

Sherry, D. F., and Vaccarino, A. L. (1989). Hippocampus and memory for food caches in blackcapped chickadess. Behav. Process 80, 334-338.

Smith, G. T., Brenowitz, E. A. and Wingfield, J. C. (1997). Seasonal changes in the size of the avian song control nucleus HVC defined by multiple histological markers. J. Comp. Neurol. 381, 253-261.

Taylor, A. H., Hunt, G. R., Holzhaider, J. C., and Gray, R. D. (2007). Spontaneous metatool use by New Caledonian crows. Curr. Biol. 17, 1504-1507.

Tomback, D. F. (1978). Foraging strategies of Clark's nutcrackers. Living Bird 16, 123-161.

Underwood, H., and Siopes, T. (1984). Circadian organization in Japanese quail. J. Exp. Zool. 232, 557-566.

Von Frisch, K., (1967). The Dance Language and Orientation of Honeybees. Cambridge, MA: Belknap. 
Wang, G., Harpole, C. E., Trivedi, A. K., and Cassone, V. M. (2012). Circadian regulation birdsong, call and locomotor activity by pineal melatonin in the zebra finch. J. Biol. Rhythms 27.

Whitfield-Rucker, M. G., and Cassone, V. M. (1996). Melatonin binding in the house sparrow song control system: sexual dimorphism and the effect of photoperiod. Horm. Behav. 30, 528-537.

Whitfield-Rucker, M. G., and Cassone, V. M. (2000). Photoperiodic regulation of the male house sparrow song control system: gonadal dependent and independent mechanisms. Gen. Comp. Endocrinol. 118, 173-183.

Wiltschko, R. (1991). The role of experience in avian navigation and homing. EXS 60, 250-269.

Yasuo, S., Yoshimura, T., Bartell, P. A., Iigo, M., Makino, E., Okabayashi, N., and Ebihara, S. (2002). Effect of melatonin administration on $\mathrm{qPer} 2$, qPer3, and qClock gene expression the suprachiasmatic nucleus of
Japanese quail. Eur. J. Neurosci. 16, 1541-1546.

Conflict of Interest Statement: The authors declare that the research was conducted in the absence of any commercial or financial relationships that could be construed as a potential conflict of interest.

Received: 20 January 2012; paper pending published: 01 February 2012; accepted: 23 February 2012; published online: 22 March 2012.
Citation: Cassone VM and Westneat DF (2012) The bird of time: cognition and the avian biological clock. Front. Mol. Neurosci. 5:32. doi: 10.3389/fnmol. 2012.00032

Copyright (c) 2012 Cassone and Westneat. This is an open-access article distributed under the terms of the Creative Commons Attribution Non Commercial License, which permits non-commercial use, distribution, and reproduction in other forums, provided the original authors and source are credited. 